\title{
LABORATORY INVESTIGATION ON THE CORRELATION BETWEEN THE FRICTION ANGLE OF ROCK JOINTS AND THE CONSTANT MI OF THE HOEK AND BROWN CRITERION
}

\author{
Tsikrikis A. ${ }^{1}$, Papaliangas T. ${ }^{2}$ and Marinos V. ${ }^{1}$ \\ ${ }^{1}$ Aristotle University of Thessaloniki, Department of Geology, 54124, Thessaloniki, Greece, tsikrik \\ a@geo.auth.gr,marinosv@geo.auth.gr \\ ${ }^{2}$ Alexander Technological Educational Institute of Thessaloniki, Department of Civil Engineering \\ TE,Thessaloniki,Greece,papaliag@cie.teithe.gr
}

\begin{abstract}
A correlation between the non-dilational friction angle $(\varphi m)$ of rock discontinuities and the constant mi of the Hoek and Brown criterion for intact rock is investigated, using the results of a focus oriented laboratory program. The program consisted of two types of laboratory tests: a series of triaxial compression tests on intact rock samples for the determination of the constant mi and an independent series of direct shear tests on tensile fractures of the same rock types for the determination of the rock joint friction angle $\varphi m$. Four typical rock types from Northern Greece were used: a granite, a sandstone, a limestone and a marble, covering a range of mi between 8 and 34 , and an unconfined compressive strength between 60 and $120 \mathrm{MPa}$. Apart from the certain range of parameters that is presented for this specific rocks, the experimental results show that the non-dilational friction angle of the rock fracture determined by direct shear testing $(\varphi m)$ decreases logarithmically with the value of the constant mi. Keywords: mi constant, direct shear tests, triaxial compressive strength, rock joints, laboratory testing, Hoek and Brown criterion.
\end{abstract}

\section{Пєрі́⿱亠乂 $\psi \eta$}

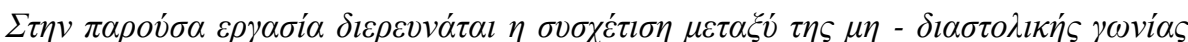

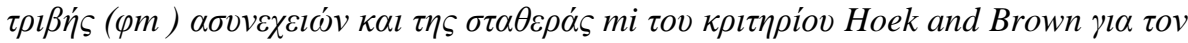

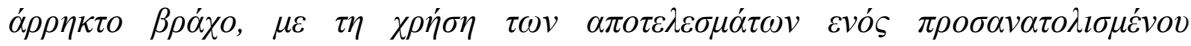

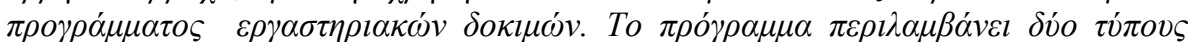

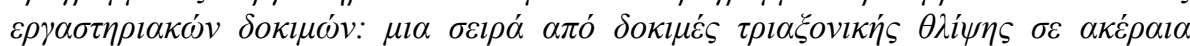

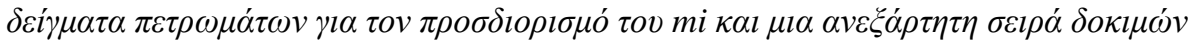

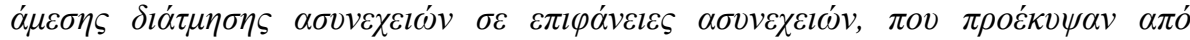

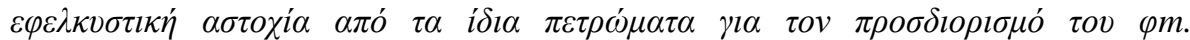

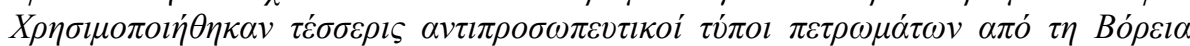

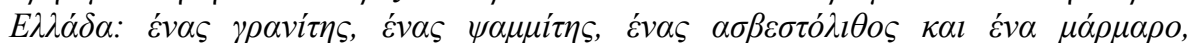

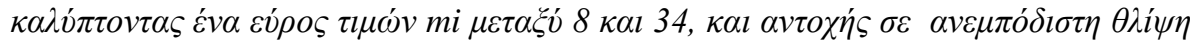

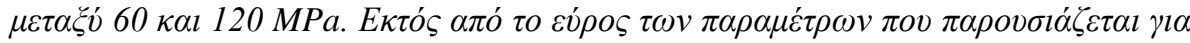

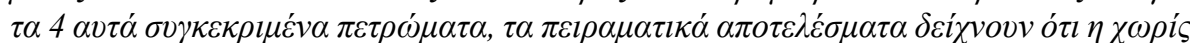

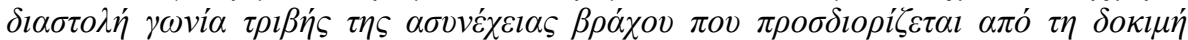

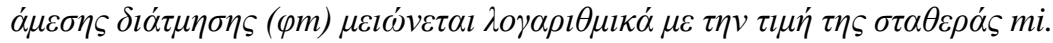




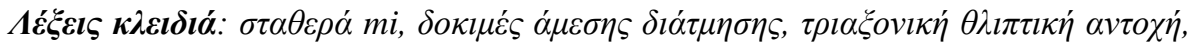

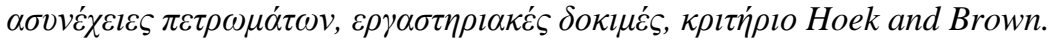

\section{Introduction}

The Hoek-Brown (H-B) failure criterion is used extensively in practice to describe the mechanical behavior of an intact rock and a rock mass (Hoek and Brown, 1980, 1970) (Hoek et al., 1992, 2002 ). In this criterion, the $\mathrm{m}_{\mathrm{i}}$ constant is an important factor which defines the slope of the initial portion of $\sigma_{1}-\sigma_{3}$ curve. This parameter is very approximately analogous to the angle of friction, $\varphi$, of the conventional Mohr-Coulomb failure criterion (Hoek, 1983). The estimation of $\mathrm{m}_{\mathrm{i}}$ is based on triaxial tests under confining pressures in the range $0-0.5 \sigma_{\mathrm{c}}$, where $\sigma_{\mathrm{ci}}$ is the unconfined compressive strength. In the absence of such tests, its value is estimated from a table of values provided by HoekBrown depending on rock type (Hoek and Marinos, 2000). From this table it can be concluded that the value of $\mathrm{m}_{\mathrm{i}}$ is higher for silicate rocks (granites and sandstones) than for carbonate ones (limestones and marbles).

On the other hand, there is adequate evidence that the friction angle $\left(\varphi_{\mathrm{m}}\right)$ of flat rock surfaces resulted from sand-blasted, rough-sawn and residual surfaces is higher for carbonate rocks than for silicate rocks (for example see Barton, 1976). Based on this remark, an investigation of the possible correlation between the friction angle of rock joints and the $\mathrm{m}_{\mathrm{i}}$ constant is hereby presented.

The determination of the parameter mi Hoek (1983) requires a data acquisition process from triaxial tests in the range $0 \leq \sigma 3 \leq 0.5 \sigma \mathrm{ci}$, as well as, data from tensile tests to anchor the envelope. The correct adjustment of the envelope and the determination of mi constant requires at least five equally spaced triaxial data points covering a confining pressure range from 0 to $0.5 \sigma \mathrm{ci}$. The nonlinear failure criterion by Hoek et al. (2002) in the generalized format is given by equation 1 .

\section{Equation 1: Hoek and Brown criterion for intact rock}

$$
\sigma_{1}=\sigma_{3}+\sigma_{c i}\left(m_{i} \frac{\sigma_{3}}{\sigma_{c_{i}}}+1\right)^{\alpha}
$$

where

$\boldsymbol{\sigma}_{1} \quad$ is the major principal stress

$\boldsymbol{\sigma}_{3}$ is the minor principal stress,

$\boldsymbol{\sigma}_{\mathbf{c i}}$ is the uniaxial compressive strength of the intact rock material

$\mathbf{m}_{\mathbf{i}} \quad$ is constant which depends on the texture and internal structure of the rock

a is a constant which controls the curvature of the envelope and depends on the properties o $\mathrm{f}$ the rock. This constant is often assumed to be equal to 0.5

The determination of the friction angle of the rock wall material $(\varphi \mathrm{m})$ was based on the Papaliangas' criterion (Papaliangas, 1995). For each shear test the measured peak shear strength is analyzed in two components of shear strength: a) The dilational (geometrical) component, which arises from overriding of asperities at an angle determined by the slope of the asperities. b) The non-dilational component, which arises from the shearing resistance rock contacts. The peak shear strength criterion used for the analysis of the experimental results is given by the following expression:

\section{Equation 2: Peak shear strength of rock joints}

$\tau_{p}=\sigma_{n} \tan \left(\varphi_{m}+\psi\right)$ 
Equation 3: Dilation angle of rock joints

$$
\tan \psi=\tan \psi_{o} \log _{10} \frac{\sigma_{n T}}{\sigma_{n}} / \log _{10} \frac{\sigma_{n T}}{\sigma_{n o}}
$$

Where:

$\tau_{\mathbf{p}} \quad$ is the peak shear stress

$\boldsymbol{\sigma}_{\mathbf{n}} \quad$ is the normal stress

$\varphi_{p} \quad$ the peak friction angle of the rock joint

$\varphi_{m} \quad$ the friction angle of the rock wall material under high normal stress and

$\psi \quad$ the instantaneous dilation angle corresponding to the peak shear strength.

$\psi_{0}$ the maximum dilation angle which is approximately equal to maximum asperity slope angle

бno is the normal stress under no-damage normal stress

$\boldsymbol{\sigma}_{\mathbf{n T}} \quad$ is the normal stress where the dilation is fully suppressed

The friction angle $\varphi m$ is different from the "basic friction angle" (Barton, 1971), and its relevance to the field shear strength of rock surfaces has been demonstrated elsewhere (Papaliangas et al., 1996, 1997). The non-dilational component of shear strength is for an effectively planar yet naturally textured surface and, for design, it can be used with a low shear strength factor of safety as a lower bound (Hencer, 1995).

\section{Laboratory test results}

The testing program consisted of a series of laboratory direct shear tests on artificially generated joints and a series of triaxial compression tests of intact core rock specimen in marble, sandstone, limestone and granite. Each rock type was from a different site of Northern Greece. The Kavala marble and Demati (Ioannina) sandstone were supplied by a local stone supplier, limestone was sampled from the quarry of Lafarge Beton at Messaio village, Kilkis and granite was sampled from the area of Arnaia, Chalkidiki. It is important to mention that, for each rock type, the specimens used for the direct shear tests and the triaxial compression tests were prepared from the same block. All laboratory tests were conducted at the Laboratory of Geomechanics of the Department of Civil Engineering TE of the Alexander Technological Educational Institute of Thessaloniki.

\subsection{Direct shear tests}

Four sets of samples were used. One set of each rock type (marble, sandstone, limestone, granite) comprises 6 samples of artificial surfaces generated by fracturing of larger samples subjected to bending tests till failure. The resulted surfaces represent the highest degree of surface roughness since they resulted from tensile failure. Each sample was subjected to multistage direct shear testing (6 different normal stresses, including one under their self weight which represents a normal stress of approximately $5 \mathrm{kPa}$ ). At the end of each stage, the sample was unloaded, the surfaces were examined and photographed and the loose debris was removed. The sample was then reset at its original position prior to changing the normal load for the next stage. The resulting total number of direct shear tests was 138 .

All samples having a length $8-12 \mathrm{~cm}$, were first tested under their self weight (negligible surface damage), so that the maximum dilation angle $\psi$ o could be determined. This is considered to represent the maximum asperity angle of the sample. Following this "zero normal load" test, the samples were subjected to shearing under higher normal stresses up to a maximum of $2.0 \mathrm{MPa}$ for the joints. All tests 
were performed using a purpose-built direct shear box, capable of accommodating samples as long as $1.20 \mathrm{~m}$ and applying a maximum shear load of $300 \mathrm{kN}$ and a maximum normal load of $250 \mathrm{kN}$.

For each data pair of shear $(\tau)$ and normal $(\sigma)$ stress the non-dilational shear and normal stress $(\tau 1$ and $\sigma 1)$ was determined using the instantaneous dilation angle $(\psi)$. These stresses represent shearing along a plane surface with natural texture, i.e. shearing without dilation (in other words shearing under constant volume conditions). This method is presented by Hencher and Richards (1989) and is based on the assumption that shearing of a dilating joint is equivalent to a shear movement along an inclined plane, having a slope angle equal to the instantaneous dilation angle. Analysis of stresses along the inclined plane $(\tau 1)$ and its perpendicular direction $(\sigma 1)$ results in the following relations:
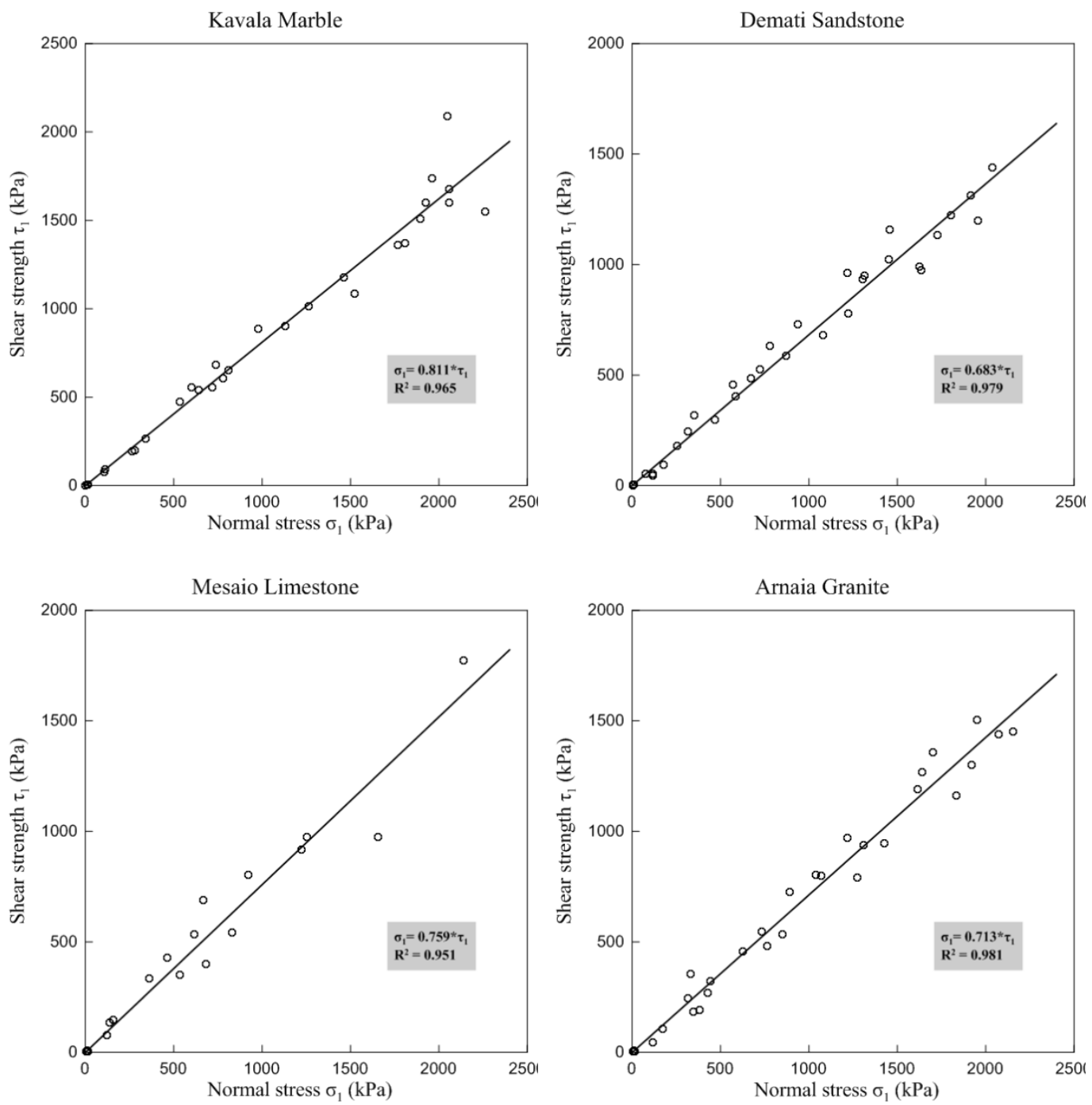

Figure 1 - Results of direct shear tests on rock joints showing the non-dilational friction line for the investigated rocks.

Equation 4: Shear stress acting on the inclined plane

$\tau_{1}=(\tau \cos \psi-\sigma \sin \psi) \cos \psi$ 
Equation 5: Normal stress acting on the inclined plane

$\sigma_{1}=(\sigma \cos \psi+\tau \sin \psi) \cos \psi$

The results presented as shear strength $\tau_{1}$ vs. normal stress $\sigma_{1}$ diagrams for all the investigated rock types are presented in Figure 1.

\subsection{Triaxial compression tests}

The triaxial compression testing program included at least eight specimens per rock type. More specifically, ten triaxial and one uniaxial for Arnaia granite, ten triaxial and two uniaxial, for Kavala marble nine triaxial and two uniaxial for Demati sandstone and eleven triaxial and one uniaxial compressive test for Messaio limestone. The total number of triaxial compression tests was 42 including 4 uniaxial compression tests. The specimens were cylindrical, with a diameter of $54 \mathrm{~cm}$ and a ratio diameter/height of 1:2. The confining pressure used for all rock types were in the range 0 to $70 \mathrm{MPa}$, however only the range between 0 and $0.5 \sigma \mathrm{ci}$ was used to determine the value of mi. All tests were carried out according to E103 - 84(6) and ASTM D7012 - 14A.

The results presented as axial strength $\sigma 1$ vs. confining pressure $\sigma 3$ diagrams for all rock types are presented in Figure 2, with the Hoek-Brown fit curve and parameters $\sigma c i$ and mi shown on each diagram. The values of mi were all within the ranges suggested by Marinos and Hoek (2000) except for the Mesaio limestone that was found to be marginally above the upper limit (15.9 vs. 15).

\section{Correlation between friction angle and constant $\mathbf{m}_{\mathrm{i}}$}

The values of the non-dilational friction angle and the constant $\mathrm{m}_{\mathrm{i}}$ of the Hoek-Brown criterion for intact rock are given Table 1.

Table 1 - Friction angle of rock joints $\varphi_{\mathrm{m}}$ and constant $\mathrm{m}_{\mathrm{i}}$.

\begin{tabular}{|c|c|c|c|c|}
\hline Rock type & Kavala marble & Messaio limestone & Demati sandstone & Arnaia granite \\
\hline $\boldsymbol{\varphi}_{\mathbf{m}}$ & $39.0^{\circ}$ & $37.2^{\circ}$ & $34.3^{\circ}$ & $35.5^{\circ}$ \\
\hline $\mathbf{m}_{\mathbf{i}}$ & 8.6 & 15.9 & 18.9 & 34.0 \\
\hline
\end{tabular}

The correlation between the two parameters in graphical form is presented in Fig.3. A logarithmic curve described by Equation 6 has been found to fit the data satisfactorily.

\section{Equation 6: Relation $\varphi_{m}-m_{i}$}

$\varphi_{m}=-2.79 \operatorname{lnm}_{i}+44.44$

The friction angle $\varphi_{m}$ appears to be independent of the normal stress and decreases from about $39^{\circ}$ for the carbonates Kavala marble and Mesaio limestone $\left(\mathrm{m}_{\mathrm{i}}=8.9\right.$ and 15.9 respectively), to about 3 $5^{\circ}$ for the silicates Arnaia granite and Demati sandstone $\left(m_{i}=34.0\right.$ and 18.9). The higher values of $\varphi_{\mathrm{m}}$ observed for the carbonates of this study as compared to those of silicates are in line with the va lues reported by Barton (1976) for the same rock types and are attributed to the difference in the fri ction angle of the corresponding rock-forming minerals. From the values of mineral friction report ed by Horn and Deere (1962), it is clear that the friction angle of calcite, the mineral constituent of marble and limestone, is clearly higher than that of quartz and feldspar, the main constituents of gr anite and sandstone. 
The value of $m_{i}$ can be determined if $\varphi_{m}$ is known by Equation 7 .
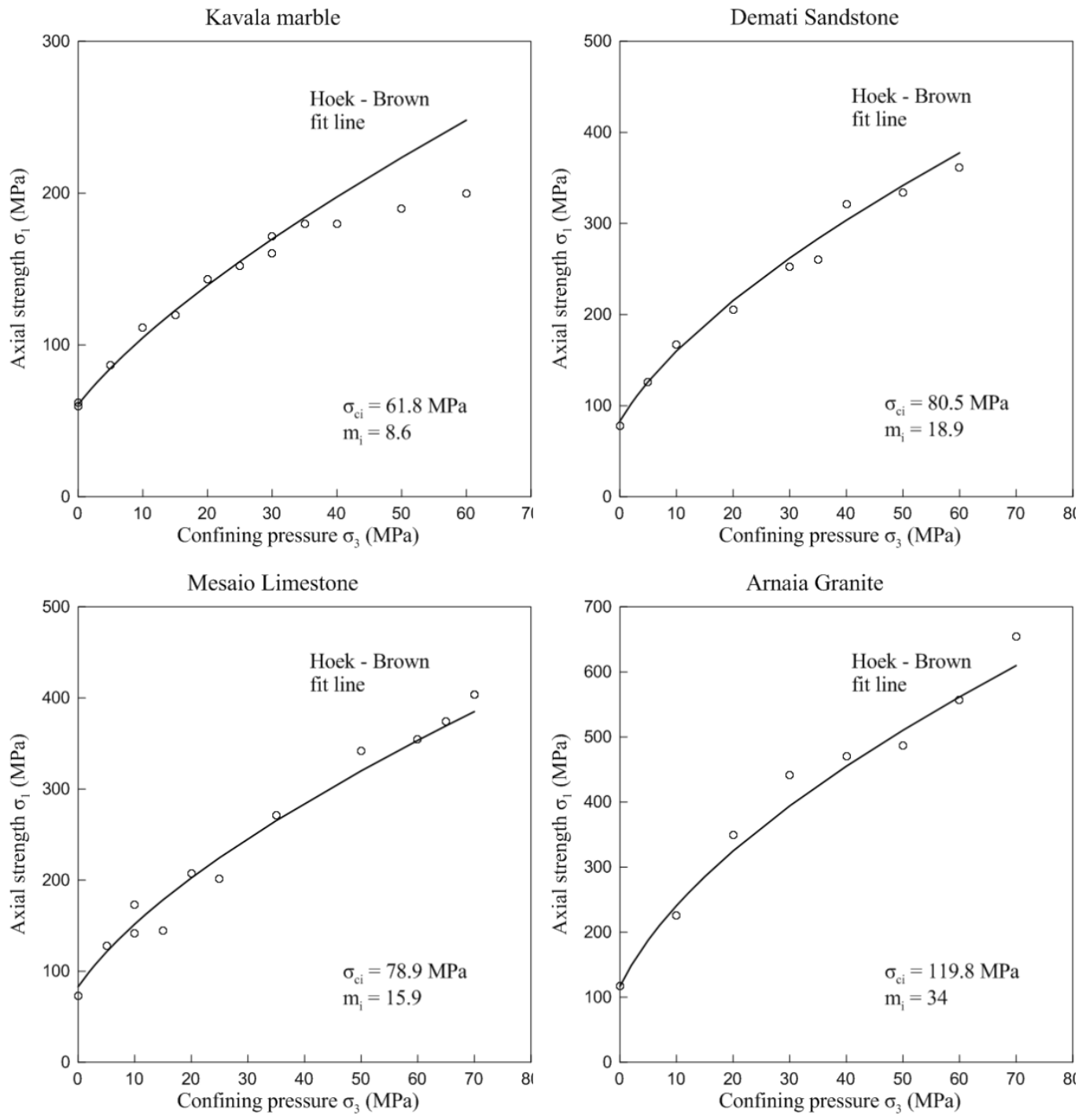

Figure 2 - Axial strength vs. confining pressure diagrams for the four investigated rocks. 


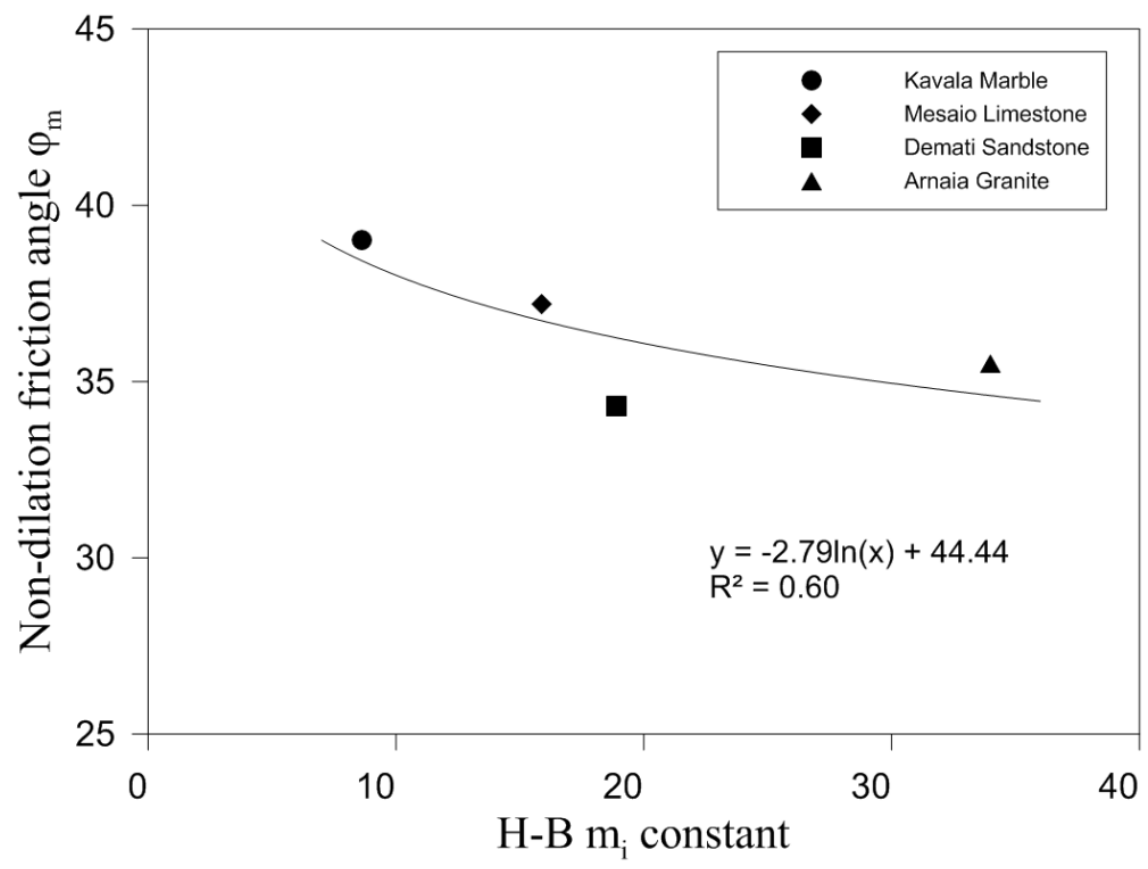

Figure 3 - Correlation between the friction angle of rock joints and the constant $\mathrm{m}_{\mathrm{i}}$ of the Hoek-Brown criterion.

Equation 7: Relation $\mathrm{m}_{\mathrm{i}}-\varphi_{\mathrm{m}}$

$m_{i}=e^{\frac{44.44-\varphi m}{2.79}}$

\section{Conclusions}

The aim of this paper was to investigate experimentally the relation between the friction angle of rock surfaces determined by direct shear testing and the constant $\mathrm{m}_{\mathrm{i}}$ of the Hoe $\mathrm{k}$ and Brown criterion for intact rock. Four different rock types were used in two types of laborator $y$ tests: a series of triaxial compression tests on intact rock samples for the determination of the con stant $\mathrm{m}_{\mathrm{i}}$ and an independent series of direct shear tests on tensile fractures of the same rock types $\mathrm{f}$ or the determination of the rock joint friction angle $\varphi_{\mathrm{m}}$.

The laboratory tests suggest that the constant $\mathrm{m}_{\mathrm{i}}$ of the Hoek and Brown criterion increases logarith mically with decreasing friction angle of the rock wall material $\left(\varphi_{\mathrm{m}}\right)$. The relation can be used to es timate the constant $\mathrm{m}_{\mathrm{i}}$ from the angle $\varphi_{\mathrm{m}}$, which is determined from direct shear testing of discontin uities and vice-versa. However, the main utility of the method is the indirect determination of the $\mathrm{c}$ onstant $\mathrm{m}_{\mathrm{i}}$ using a series of direct shear tests on discontinuities from the same rock, when suitable $\mathrm{t}$ riaxial compression test results are not available. It should be noted that the correct determination o $\mathrm{f}_{\mathrm{i}}$ constant requires at least five cylindrical specimens for the production of five equally spaced $\mathrm{t}$ riaxial data points covering a confining pressure range from 0 to $0.5 \sigma_{\text {ci. }}$ On the other hand, for the $d$ etermination of $\varphi_{\mathrm{m}}$ a multi-stage direct shear test on a single rock joint sample of any shape tested under three different normal stresses is acceptable (ISRM, 2014).

Another important contribution of this method is the estimation of $\mathrm{m}_{\mathrm{i}}$ for weathered rocks. Direct $\mathrm{s}$ hear test on weathered rock joints can be carried out without any experimental difficulty, whereas c ylindrical specimens for triaxial testing require coring from weathered rock pieces, which is quite $\mathrm{d}$ ifficult. Therefore, the decrease in the value of $m_{i}$ for a weathered intact rock sample can be estima ted by this method. 
The relation between the two parameters described earlier resulted from only four different rocks $\mathrm{t}$ ypes which covered the range of constant $\mathrm{m}_{\mathrm{i}}$ between 8 and 34. Consequently, the equation gives o nly a trend and not an accurate estimate of the constant $\mathrm{m}_{\mathrm{i}}$ from $\varphi_{\mathrm{m}}$. To establish a more accurate $\mathrm{e}$ xpression, a number of additional different rocks types needs to be used. Moreover, for further deta iled investigation of the correlation, specimens subjected to triaxial compressive tests can be used a fterwards for direct shear testing.

\section{References}

ASTM D7012-14A, 2014. Standard Test Methods for Compressive Strength and Elastic Moduli of Intact Rock Core Specimens under Varying States of Stress and Temperatures, ASTM International, West Conshohocken, PA.

Barton, N., 1971. A Relationship Between Joint Roughness and Joint Shear Strength, Proc. ISRM Symp.on Rock Fracture, Nancy, France, Pap. I-8.

Barton, N., 1976. The Shear Strength of Rock and Rock Joints, Int. J.Rock Mech. Min. Sci. and Geomech., 13, 255-279, Pergamon Press.

Hoek, E., 1983. Strength of jointed rock masses, $23^{\text {rd }}$ Rankine Lecture, Géotechnique, 33(3), 187-223.

Hoek, E. and Brown, E.T., 1997. Practical estimates of rock mass strength, International Journal of Rock Mechanics and Mining Sciences, 34 (8), 1165-1186.

Hoek, E. and Brown, E.T., 1980. Empirical strength criterion for rock masses, J Geotech Eng Div ASCE, 106(GT9), 1013-1035.

Hoek, E., Carranza-Torres, C. and Corkum, B., 2002. Hoek-Brown criterion - 2002 edition. In: Proceeding of the NARMS-TAC Conference, Toronto, 1, 267-273.

Hoek, E., Wood, D. and Shah, S., 1992. A modified Hoek-Brown failure criterion for jointed rock masses, ISRM Symposium on Rock Characterization, Chester, UK.

Hencher, S.R. and Richards, L.R., 1989. Laboratory direct shear testing on rock discontinuities, Ground Engng, 22, 24-31.

Hencher, S. and Richards, L., 2014. Assessing the shear strength of rock discontinuities at laboratory and field scales, Rock Mechanics and Rock Engineering, 48, 883-905.

Horn, H.M. and Deere, D.U., 1962. Frictional characteristics of minerals, Géotechnique, 12, 319-35.

ISRM, 2014. Suggested Method for Laboratory Determination of the Shear Strength of Rock Joints: Revised Version, Rock Mechanics and Rock Engineering, 47(1), 291-302.

Papaliangas, T.T., Hencher, S.R. and Lumsden, A.C., 1995. A comprehensive peak shear strength criterion for rock joints. In: Fuji, T., ed., Proc. 8th Int. Congress ISRM, Tokyo, 1, 359-366, Rotterdam, Balkema.

Papaliangas, T.T., Lumsden, A.C. and Hencher, S.R., 1996. Prediction of in situ peak shear strength of rock joints. In: Barla, G., ed., EUROCK' 96. Prediction and Performance in Rock Mechanics and Rock Engineering, Proc. ISRM Symposium, Torino, 2-5 September. Rotterdam, Balkema.

Papaliangas, T.T., Lumsden, A.C. and Manolopoulou, S., 1997. Rock slides and assessment of insitu joint shear strength. In: Marinos, P., et al., eds., Engineering Geology and the Environment, Proc. Intern. Symp., Athens, 23-27 June 1997, Vol. 1. Rotterdam, Balkema. 